\title{
UMA EXPERIÊNCIA DE CTS EM SALA DE AULA: A INTERNACIONALIZAÇÃO DA AMAZÔNIA
}

\author{
AN EXPERIENCE OFCTSINTHE CLASSROOM: THEINTERNATIONALIZATIONOF THE \\ AMAZON
}

André Luiz Rodrigues Chaves ${ }^{1}$

Álvaro Chrispino ${ }^{2}$

\begin{abstract}
RESUMO
O estudo constitui-se na construção e aplicação de uma sequência de ensino-aprendizagem, construída de forma coletiva com visão interdisciplinar, voltada para a discussão em torno do tema "internacionalização da Amazônia", seguindo os pressupostos de uma abordagem CTS, por meio da técnica da controvérsia controlada, aplicada em uma escola privada de ensino médio da cidade do Rio de Janeiro. Inicia-se com uma breve digressão sobre o ensino voltado para o desenvolvimento de competências, uma revisão sobre a história das abordagens CTS, as suas implicações para um ensino de ciências voltado para a construção de uma aprendizagem significativa. As questões centrais que balizaram a pesquisa visaram a identificar os seguintes elementos: as ideias prévias que os estudantes tinham sobre os assuntos relacionados à Internacionalização da Amazônia;as formas como os estudantes e os professores se integraram à metodologia utilizada;a maneira com que os estudantes lançavam mão dos conceitos científicos diante das demandas situacionais referentes a um problema proposto;a contribuição do projeto proposto para o desenvolvimento de competências e habilidades cognitivas visando à formação cidadã dos estudantes.A análise do processo baseou-se teoricamente no Estudo de Caso a partir do enfoque CTS como forma de promoção da alfabetização científica.
\end{abstract}

Palavras-chave: CTS; ensino de ciências; controvérsia controlada

\begin{abstract}
The study is based on the construction and application of a sequence of teaching and learning, built collectively with an interdisciplinary vision and focused on a discussion about the topic "Internationalization of Amazon" following a STS approach, by means of the controlled controversy technique applied on a private High School of Rio de Janeiro. It begins with a brief digression on teaching as a skill developer, a review about the story of the STS approach and its implications to scientific teaching as a significant learning way. The main questions that guided the research aimed to identify the following elements: student's previous ideas about subjects related to the Internalization of Amazon; the ways in which students and teachers have integrated themselves to the methodology used; the way in which students would use scientific concepts regarding a proposed problem; the proposed problem's contribution to the development of competences and cognitive skills, in order to form citizens

\footnotetext{
1 Professor do Departamento de Matemática do Colégio Pedro II e Consultor Pedagógico do Grupo Mopi, RJ; andre.chaves@mopi.com.br

2 Professor do Programa de Pós-graduação stricto sensu em Ensino de Matemática e Ciências do CEFET/RJ; alvaro.chrispino@gmail.com

AMAZÔNIA - Revista de Educação em Ciências e Matemáticas V.9 - no17 - jul. 2012/dez. 2012, p.122-140
} 
out of students. The analysis of the process was theoretically founded on Case Study, trough the STS focus as a promotion of the scientific alphabetization.

Key-words: STS Approaches; High School; Controlled Controversy

\section{INTRODUÇÃO}

Desde a promulgação da Lei de Diretrizes e Bases da Educação Nacional, em 1996, a educação básica deve assumir uma configuração com vistas à formação de pessoas e de profissionais competentes para a vida em sociedade e para a atuação no universo do trabalho.

Em decorrência disso, a meta precípua da escola é o desenvolvimento das ditas competências pessoais, prevalecendo sobre o usual ensino dos conteúdos disciplinares. Estes têm sido organizados em programas disciplinares, construídos de forma fragmentada, superestimando aspectos técnicos em detrimento da significação dos conteúdos estudados.

Outrossim, em vários aspectos, como forma de tentar mitigar o problema, associa-se ao ensino um sentido de utilidade ou de praticidade, que pode gerar uma visão meio deturpada da real dimensão do processo de aprendizagem. Pergunta-se: "para que serve isso?" ou "onde isso será aplicado?" ou "qual a utilidade de aprender isso?", em busca da justificação de se ensinar alguns conteúdos em detrimentos de outros. Segundo afirma Pedro Demo, em "Aprender: desafio reconstrutivo": "prático não é somente o que tem utilidade imediata, mas aquilo que resolve a proposta de trabalho de modo mais profundo" (DEMO, 1998), Mas, o ensino atual, como se vem observando, não tem logrado êxito nesse sentido, pelo menos, da maneira que deveria. Ainda citando o mesmo autor:"O ensino, sobretudo o mero ensino, dificilmente é prático, porque esconde uma visão mecânica de prática. Distribuir fórmulas feitas é atrapalhar a vida das pessoas. Sobretudo, se as rebaixamos a entes passivos que seguem ordens dos outros" (DEMO, 1998).

Mas nem sempre foi assim. A História da Ciência mostra, na Grécia, a partir de um dos primeiros currículos de que se tem conhecimento na cultura ocidental, o Trivium, a existência de três disciplinas essenciais para a formação do homem grego. Eram elas: a Gramática (o uso correto da língua materna); a Lógica (desenvolvimento adequado da argumentação); e a Retórica ("ela é a arte de persuadir, não a de encontrar a verdade”3). Havia também o Quadrivium, constituído de quatro disciplinas que lidavam com números -aritmética, geometria, música e astrologia ou astronomia.

${ }^{3}$ Olavo de Carvalho em http://www.olavodecarvalho.org/apostilas/pensaris1_1.htm 
As disciplinas do Triviume do Quadrivium não tinham por objetivo a formação de especialistas em determinada área de atuação, mas a formação de políticos, pessoas habilitadas para a participação efetiva na vida da polis. Aqueles que não tinham essa habilitação ou que não desejavam ocupar-se com a vida da polis eram chamados de idiotas. Assim, o conhecimento era percebido em sentido amplo, lato sensu.

O domínio das disciplinas que integravam o Trivium e o Quadrivium foi considerado, por quase dois mil anos, a condição básica para o ingresso nos estudos filosóficos. Na Idade Média européia, os estudos começavam na adolescência, pelo Trivium e Quadrivium, que duravam mais ou menos dez anos de aprendizado. Em seguida, entrava-se numa das três faculdades - Direito, Medicina ou Filosofia.

Porém, notadamente a partir do século XVII, observa-se a prevalência do conteúdo científico sobre outras formas de conhecer, de modo que um método de investigação passou a ser sinônimo de conhecimento, em stricto sensu.

Com isso, estudar e fazer ciência ganhou o status de promotor de saber, delineando os caminhos para se concretizar o bem-estar social e, particularmente, balizar o trabalho escolar. Destarte, na escola, os objetivos educacionais passaram a ser organizados como consequência direta daqueles que caracterizam o desenvolvimento da ciência.

Conquanto essa forma de ver a implicação "ciência + tecnologia $\rightarrow$ bem-estar" tenha vigido por bastante tempo, a crise advinda a partir dasações sociais que originaram o surgimento do movimento CTS, trouxe à tona a percepção de que o desenvolvimento científico não deve ser considerado um valor em si, nem deve ser desvinculado da intencionalidade que o cerca. Ou seja, ganha-se a dimensão de que a ciência, bem como a tecnologia, devem ser encaradas como meios para possibilitar a realização dos projetos pessoais e coletivos, em busca de uma sociedade melhor para todos. Como afirma Casassus (2007), "se antigamente a ciência e a tecnologia eram importantes somente para as pessoas que dirigiam para as carreiras científicas, hoje isto mudou, pois as tecnologias com base matemática moldam nossa existência”. Ou, ainda, segundo Reis e Galvão (2005),

\footnotetext{
“(...) numa sociedade científica e tecnologicamente avançada, o exercício da cidadania e a democracia só serão possíveis através de uma compreensão do empreendimento científico e das suas interações com a tecnologia e a sociedade que permita, a qualquer cidadão, reconhecer o que está em jogo numa disputa sociocientífica, alcançar uma perspectiva fundamentada, e participar em discussões, debates e processos decisórios".
}

Mas, essas novas concepções implicaram uma acirrada disputa entre competências e conteúdos. Segundo alguns, o trabalho objetivando um deles impedia a realização do trabalho 
visando ao outro. Hoje, após uma miríade de conflitos, entende-se o objetivo educacional como sendo "reorganizar o trabalho escolar a fim de revitalizar os significados dos currículos como mapas do conhecimento que se busca e da formação pessoal como a constituição de um amplo espectro de competências" (MACHADO, 2010).

Ao propor a integração de ações ordenadas com o objetivo de realizar alguma coisa, ou, ainda, como diz ZABALA (1998), a reflexão sobre princípios ou ideias éticas que permitem às pessoas emitir um juízo sobre as condutas e seu sentido, há um abalo generalizado sobre os atores que integram o cenário escolar. Faz-se necessário fazer para aprender, pensar e repensar constantemente sobre esse fazer. Esta equação que se retroalimenta pode ser satisfeita de alguma forma com a proposta de ensino CTS.

\section{O ENFOQUE CTS}

Em termos formais, pode-se assumir que o período que vai da Revolução Industrial até o início da década de 1970 foi aquele em que se cria na linearidade, na qual a tecnologia, muitas vezes fruto dos avanços científicos, conduzia automaticamente ao progresso e à melhoria da vida humana.Aceitava-se a ideia de que tanto a ciência como a tecnologia representavam a solução para a maioria dos males da sociedade (REIS, 2008).

A implicação se verificou, ou seja, os avanços científicos e tecnológicos no campo da saúde, da indústria em geral, etc. efetivamente permitiram melhorar as condições de vida de uma parte expressiva população. No entanto, os custos ambientais e humanos, bem como a gama de problemas agravados por tais avanços, a cada dia, ganham evidência, acarretando cada vez mais uma série de dilemas e contradições em relação à utilização destas novas tecnologias e seus impactos para a espécie humana. Verifica-se também que o avanço tecnológico parece acarretar uma maior distância entre ricos e pobres, no que concerne a aquisição de oportunidade e de acesso a bens de consumo que favorecem a inclusão digital efetiva, por exemplo.

Na década de 1960, com a Guerra do Vietnam, em que foram utilizadas algumas armas químicas, aliado à tomada de consciência em virtude das consequências advindas do uso das armas nucleares na $2^{\mathrm{a}}$ Guerra Mundial, à observação de problemas ambientais que instaram questionamentos acerca da qualidade de vida da sociedade da época e à valorização da ética, se percebeu ser necessário ter a participação dos cidadãos de forma crítica e 
autônoma nas tomadas de decisões em questões públicas, retirando o controle que até então estava nas mãos dos cientistas (TERRAZAN et al., 2009).

Surge então um novo olhar para a ciência e, por conseguinte, para a tecnologia, colocando-as sob uma visibilidade na medida em que ao bem estar social podem estar vinculados impactos para os quais a sociedade não tem preparo para lidar.

Essa miríade de impactos de naturezas diversas, mas tendo em comum conter uma resposta à insatisfação à chamada concepção tradicional da ciência e da tecnologia, conduziram à formação de movimentos sistematizados tanto de cunho acadêmico, como de cunho social, que passaram a discutir, com matizes diferenciados, a relação, e os conflitos advindos desta relação, entre a ciência, a tecnologia e a sociedade.

Se, antigamente, nos tempos anteriores à Revolução Científica, vivia-se numa sociedade do medo dos mitos originados do desconhecimento da natureza, hoje, instituiu-se uma sociedade do medo do que se fará em face do poder desconhecido que se possui, numa relação em que as benesses científico-tecnológicas dominam a sociedade, gerando uma espécie de conflito entre ambos.

Segundo Giddens (1997):

“[...] as relações entre o desenvolvimento do conhecimento humano e o autoentendimento humano provaram ser mais complexas do que pensavam os filósofos do Iluminismo. Esses pensadores acreditavam que aumentar o conhecimento produzido com respeito aos mundos social e natural conduziria a uma maior certeza sobre as condições sob as quais conduzimos nossas vidas e, assim, sujeitaria à dominação humana o que outrora fora o domínio de outras influências. $\mathrm{O}$ autor afirma que, atualmente, a característica de nossas vidas é o que se poderia chamar de incerteza fabricada".

Assim foi que, em 1962, a publicação de duas obras mexeu com as bases das concepções de Ciência e Tecnologia - "Silent Spring" de Rachel Carson, que discute questões relacionadas ao uso de inseticidas como o DDT, e "A Estrutura das Revoluções Científicas", de Thomas Kuhn, que questiona a concepção tradicional de ciência -, trazendo para o cenário, a reivindicação de algum controle da sociedade sobre a atividade científico-tecnológica.

Concluindo, e respeitando a proposta de narrativa sintética, o que a história deve nos legar é a inadequação de dissociar ciência, tecnologia, sociedade do contexto histórico, cultural, político, ambiental, econômico e social em que vivemos ou mesmo nos deixar levar por uma inocência de que os processos são desprovidos de intenções, conforme afirma Cutcliffe (1990), “[...] os estudos CTS são um reflexo de uma época em que se busca exercer uma influência social e política mais forte e deliberada sobre a ciência e a tecnologia". 
O enfoque CTS, na escola, certamente contribui para a realização de um trabalho que, de forma eficiente, consegue atingir os objetivos do letramento científico. Lembrando o que disse Gordillo (2003):

“[...] se tivéssemos que enunciar em poucas palavras o propósito dos enfoques CTS no campo da educação, seria possível resumir em dois pontos: mostrar que a Ciência e a Tecnologia são acessíveis e importantes para os cidadãos (portanto, é necessária a Alfabetização Tecno-científica) e propiciar o aprendizado social da participação pública nas decisões tecno-científicas (portanto, é necessária a educação para a participação também em Ciência e Tecnologia)".

Portanto, há que se estruturar uma metodologia de ensino que, sem abalar o que existe, tanto dê conta de apresentar conteúdos e conceitos de forma consistente, como tire a ciência da posição de falsa neutralidade, que desequilibre o modelo linear de desenvolvimento, além de promover o desenvolvimento de conteúdos procedimentais e atitudinais vinculados às habilidades e competências cognitivas desconhecidas na escolaridade padrão, pois, afinal, conforme Gallagher (1971, citado por AIKENHEAD 2003):

\footnotetext{
"Para futuros cidadãos em uma sociedade democrática, compreender a inter-relação entre ciência, tecnologia e sociedade pode ser tão importante como entender os conceitos e os processos da ciência”.
}

Segundo Santos (2001), são "pontos chave" da educação CTS: proporcionar aos alunos meios para emitirem julgamentos conscientes sobre os problemas da sociedade; proporcionar uma perspectiva mais rica e mais realista sobre a história e a natureza da ciência; tornar a ciência mais acessível e mais atraente a alunos de diferentes capacidades e sensibilidades, e preparar os jovens para o papel de cidadãos numa sociedade democrática, mesmo que alguns destes pontos nos pareçam utópicos ou de difícil alcance.

Outrossim, os processos de ensino e de aprendizagem passam a ter uma função de despertar nos alunos a curiosidade, o espírito investigador, questionador e transformador da realidade, rompendo assim a concepção tradicional predominante em nossas escolas, nas quais se reduz a compreensão dos conceitos à mera reprodução de regras e de leis.

Destarte, em linhas gerais, conquanto o conceito de CTS não seja consensual, como campo de ação educacional,esta abordagem oferecemuitas possibilidades de ações e de intervenções no Ensino Médio, em que existem desafios claros, oriundos da organização curricular, da falta de formação e de informação docente, que precisam ser encarados com celeridade a fim de se alcançar uma formação efetivamente cidadã.

Dentre as necessidades mais sensíveis, estáa falta de professores habilitados para estabelecer este ambiente de sala de aula, em que se pratique, com relativa naturalidade, o estímulo à comunicação, o desenvolvimento da autonomia, a reflexão e a ação. Segundo 
Penick (1993, citado por REIS, 2008), as características dos professores que se revelam decisivas para o sucesso do enfoque CTS são:

\begin{abstract}
"1. Despender tempo com o planejamento dos processos de ensino-aprendizagem e com a avaliação dos seus resultados, tendo em vista a sua melhoria; 2. Interpretar o currículo e a sua própria programação de forma flexível; 3. Proporcionar um clima afetivamente acolhedor e intelectualmente estimulante com o objetivo de promover a interação e a comunicação na sala de aula; 4. Possuir expectativas elevadas relativamente a si próprio e aos alunos; 5. Evidenciar um desejo constante de aprender novos conhecimentos (nomeadamente, científicos, tecnológicos e pedagógicos) através de pesquisa autônoma ou em interação com seus colegas e alunos; 6. Suscitar o aparecimento de perguntas e temas de interesse na aula; 7. Pedir aos seus alunos para fundamentarem sempre as suas ideias; 8. Promover a aplicação dos conhecimentos ao mundo real; 9. Destacar as potencialidades da ciência e da tecnologia sem, contudo, ocultar as suas limitações na resolução de problemas sociais complexos; 10. Desenvolver nos alunos a confiança e as capacidades necessárias à utilização com êxito da ciência e da tecnologia; 11 . Ultrapassar a barreira imposta pelas paredes da sala de aula, estabelecendo intercâmbios com o exterior e educando para a vida".
\end{abstract}

Portanto, a fim de robustecer ações que contemplem um enfoque CTS no Ensino Médio, torna-se imprescindível que haja suporte para que os professores desse nível de ensino possam, pelo menos, refletir sobre a sua prática e sobre os conhecimentos com os quais trabalham, visando ao estabelecimento dos processos de ensino e de aprendizagem dos alunos.

\title{
O REFERENCIAL TEÓRICO
}

Em virtude da natureza do trabalho desenvolvido, tomou-se para aporte teórico o Estudo de Caso, o qual pode ser sucintamente definido como uma exploração de um sistema delimitado ou de um caso, obtido por meio de uma detalhada coleta de dados, envolvendo múltiplas fontes de informações (CRESWELL, 1998). É um estudo aprofundado de uma unidade, grupo ou indivíduo, em sua complexidade e em seu dinamismo próprio, fornecendo informações relevantes para a tomada de decisão (LÜDKE e MEDA, 1986).

Uma etapa crucial foi a escolha do tema que seria objeto de estudo. Um tema que mereça investigação deve ser ao mesmo tempo importante, original e viável. Um tema será importante quando, de alguma forma, for ligado a uma questão que polariza e afeta um segmento substancial da sociedade (MARTINS, 2006). Tendo isso em mente, a escolha da discussão sobre a Internacionalização da Amazônia, por meio de uma abordagem CTS, usando o recurso da controvérsia controlada, foi ao encontro do pressuposto teórico.

Ademais, em uma de suas etapas, foi fundamental a associação da pesquisa com a ação, com vistas à elucidação de questões suscitadas, na estruturação do projeto do trabalho. 
Esta etapa envolveu os professores que integraram o projeto, os quais coletivamente buscaram e experimentaram soluções diante de situações reais que surgiam numa verdadeira integração de produção e de uso de conhecimento. Essa estratégia, segundo descrito em MARTINS (2006), é adequada aos propósitos de um Estudo de Caso, consistindo no que se intitula, conforme Thiollent (1984, citado por MARTINS, 2006), Pesquisa-Ação, que é

“[...] um tipo de pesquisa social com base empírica que é concebida e realizada em estreita associação com uma ação ou com a resolução de um problema coletivo e no qual os pesquisadores e os participantes representativos da situação ou problema estão envolvidos de modo cooperativo ou participativo".

O trabalho em tela foi uma intervenção pedagógica realizada durante cinco meses, em 2008, o qual se caracterizou por ser interdisciplinar, visando à aprendizagem significativa, utilizando-se da técnica da controvérsia controlada. Segundo Chrispino (2008), a controvérsia controlada pode ser definida como:

"um método didático de construção de consenso (pelo menos no processo de
debate) minuciosamente preparado a partir de regras previamente definidas visando
o exercício de (1) identificação de problemas comuns para fomentar a controvérsia;
(2) o exercício de estabelecer padrões mutuamente aceitáveis para sustentar um
debate; (3) a busca organizada de informações pertinentes ao tema definido; (4) a
preparação da exposição em defesa da posição; (5) a capacidade de escutar a
posição controversa apresentada racionalmente pelos demais participantes; (6) o
exercício de contra-argumentar a partir do conhecimento dos argumentos utilizados
pelos demais debatedores e (7) reavaliar as posições - a sua e as demais - a partir de
novas informações."

Assim:

(a) Em (1), o tema controverso é colocado por meio de formas, que estimulam uma reflexão a seu respeito, causando uma espécie de imersão na controvérsia com a realização do que Piaget chamaria de desequilíbrio cognitivo;

(b) Em (2), são estabelecidas as regras que irão delinear o debate com vistas a promover uma interlocução efetiva;

(c) Em (3), a fim de um efetivo desempenho no debate, far-se-á necessária a aprendizagem dos envolvidos acerca dos pontos que lhes competem defender bem como daqueles de que terão que se defender;

(d) Em (4), após a reunião do material visando à aprendizagem, vem a preparação da forma como será a apresentação ao longo do debate, ou seja, não basta ser um profundo conhecedor do tema se não houver uma capacidade de expor, tanto oralmente como por meio de um texto, os conhecimentos que se têm; 
(e) Em (5), está uma das mais importantes etapas de um debate que é capacidade de ouvir o posicionamento dos demais sendo imprescindível que o estudo realizado em (3) tenha lhe dado conhecimento suficiente para, nesse momento, não estar diante de situações para as quais não se esteja preparado.

(f) Em (6), a partir da exposição dos outros, elaborar redarguições consistentes e pertinentes;

(g) Em (7), estar constantemente atento para ser arguto o suficiente para mudar os rumos, redefinindo estratégias ou estabelecendo novas ações que visem à retomada de possíveis situações adversas.

Naturalmente, uma técnica com tamanha complexidade de execução e ambiciosos objetivos pedagógicos requer uma temática apropriada, algo que de fato se configure uma controvérsia. Ainda, segundo Chrispino (2008):

Para que se cumpram todas as etapas didáticas, o tema a ser utilizado na controvérsia deve combinar a interdependência social com o conflito intelectual, visto que quanto maior for o número de elementos potencialmente cooperativos, e menor o número de elementos competitivos, mais construtivo será o conflito e a controvérsia. Importante perceber que não é somente o componente cooperativo que contribui para uma controvérsia mas, também, o componente conflito, visto que é este que permitirá a chance de ouvir outras posições e refletir sobre elas.

Controvérsias oriundas dos debates ambientais, das discussões acerca dos limites da ciência ou os infindáveis questionamentos envolvendo moral e ética na política são alguns exemplos de fontes inexoráveis de temas com características adequadas para um trabalho em controvérsia controlada.

As simulações CTS pretendem ser uma alternativa educativa para propiciar a aprendizagem social da participação nas controvérsias tecno-científicas. Daí que seu principal significado não está na veracidade última de suas propostas, mas sim em sua verossimilhança e relevância social e educativa.

Assim, para os casos de controvérsia controlada, Chrispino (2008), citando Gordillo e Osório (2003), propõe uma lista de materiais imprescindíveis para a consecução efetiva do trabalho: uma noticia real ${ }^{4}$, que se apresenta aos alunos no formato de um jornal real, e de onde se parte para o desenvolvimento da controvérsia de que se deseja tratar; um questionário inicial e final, que serve para conhecer as informações e as atitudes prévias dos alunos sobre as questões objeto do trabalho, e para demonstrar as mudanças produzidas ao final da

\footnotetext{
${ }^{4}$ Os autores propõem uma notícia fictícia, porém verossímil. Cremos que a realidade brasileira está repleta de temas que possam servir de ponto de partida para a controvérsia, além do que a realidade é um espetacular motivador de estudos e debates.
} 
atividade; uma rede de atores que aparece na controvérsia descrita na noticia inicial, e cujos perfis representem efetivamente os grupos com posições contrárias que estabelecerão a controvérsia; documentos obtidos para dar apoio aos argumentos dos atores participantes, relacionando o conhecimento específico da área que o caso trata com o centro da controvérsia simulada; documentos selecionados por sua pertinência e claridade para apresentar a informação científica do campo em que se situa controvérsia; fichas específicas em que cada equipe escreve seus argumentos, como vai defendê-los, antecipa a posição contrária das demais equipes e os argumentos que possui, bem como aqueles que utilizará para rebatê-los; fichas contendo os critérios de avaliação para a equipe e para os membros de cada equipe.

O tema que estava em discussão, ainda fora da grande imprensa, por volta de março de 2008, dizia respeito aos embates da então Ministra do Meio Ambiente, Marina Silva, com pessoas do próprio governo Lula, acerca de questões referentes à preservação da Floresta Amazônica.

Esse tema congregava, de maneira bastante ampla, os requisitos descritos nas revisões bibliográficas, além de abarcar aspectos gerais relativos à discussão socioambiental, sintetizada a seguir:

\begin{abstract}
Vivemos tempos de insegurança e incerteza face ao futuro. Não se trata de uma incerteza social, mas de uma incerteza ecológica que põe em causa a sobrevivência de inúmeras espécies incluindo a nossa. No nosso quotidiano, somos confrontados com situações tão críticas como as mudanças climáticas, o recurso aos transgênicos, a energia nuclear, a desflorestação, a fome e a pobreza extrema ou a sobrepopulação do planeta. Conceitos como Desenvolvimento Sustentável e Educação para a Sustentabilidade fazem parte da linguagem do dia-a-dia, mas nem sempre os seus significados são alvo de reflexão e crítica (FIGUEIREDO, 2006).
\end{abstract}

Ademais, com vistas a adensar a discussão, circulava pela imprensa internacional notícias de caráter fantasioso, dando conta na necessidade de intervenção internacional na floresta como forma de preservar aquele que seria um patrimônio da humanidade, resultando um artigo escrito pelo Senador Cristovam Buarque ${ }^{5}$ (PDT-DF), muito divulgado à época.

Um dos ingredientes de maior relevância dentro do tema em análise é o aquecimento global,que, indubitavelmente, suscita controvérsias diversas. Nessa questão, suas causas e consequências, a complexidade das discussões é de tal ordem, que mesmo a comunidade científica não consegue chegar a um ponto de convergência. Epstein (2002) afirma que as questões de ordem científica, os custos dos prejuízos e os custos das mudanças climáticas, as pressões dos grupos interessados, as consequências eleitorais das medidas econômicas propostas e as questões de natureza ética são justificativas para a complexidade referida.

${ }_{5}^{5}$ Disponível em http://www.portalbrasil.net/reportagem_amazonia.htm 
A Floresta Amazônica na e sob a qual se escondem mistérios, que tantos desejam explorar, há muito vem sendo alvo da cobiça externa.Por diversas vezes, de maneira direta ou indireta, essa aguçada cobiça instiga a proposição da internacionalização da Floresta Amazônicasob a alegação de ser ela um patrimônio da humanidade, que requer cuidados negligenciados pelo Governo Brasileiro.

Portanto, ficou configurado aí um tema perfeito para se propor uma simulação CTS, na medida em que nele havia ingredientes suficientes como: uma série de ações de consequências sociais graves oriundas do desejo externo pela internacionalização da Amazônia, a qual poderia garantir sua preservação, mas, ao mesmo tempo, permitir a exploração de seus recursos naturais. Esse ponto por si já é controverso, uma vez que a exploração dos recursos naturais implicaria a implantação de indústrias e a consequente rede estrutural de que elas necessitam, acarretando impactos ambientais de desdobramentos inusitados.

Destarte, sua discussão por meio de organismos representativos de vários segmentos da sociedade internacional possibilitou, diante da controvérsia colocada, o exercício da reflexão acerca das atividades tecno-científicas, das questões econômico-financeiras, dos valores em termos morais e éticos e, com isso, ajudou a "construção da aprendizagem da convivência de grupos com ideias e posições distintas e o conflito salutar de ideias divergentes, sobre o qual se estrutura uma sociedade democrática" (CHRISPINO, 2005).

\section{DESCRIÇÃO DO TRABALHO}

A primeira etapa da estruturação do trabalho consistiu em, após escolher um tema relevante - A Internacionalização da Amazônia -, e a metodologia a ser utilizada - a controvérsia controlada -, redigir um projeto baseado na proposta elaborada por Chrispino (2005).

A segunda etapa envolveu a formação do grupo de professores que iria desenvolver o projeto. Foram convidados os professores do $1^{\mathrm{o}}$ ano do Ensino Médio, responsáveis pela regência das disciplinas Biologia, Filosofia, Física, Geografia, História, Química e Informática, sob a supervisão do Coordenador do Segmento. O grupo ficou então constituído por nove professores, dos quais, oito efetivamente atuando em sala de aula e, um capitaneando o processo de pesquisa (o professor André Chaves). 
Ao longo dos quatro meses seguintes, foram realizadas reuniões periódicas com o objetivo de discutir detalhadamente cada etapa do projeto, bem como a forma de desenvolvimento do trabalho de cada um. A opção por uma metodologia de participação interativa propiciou que cada professor interviesse diretamente no processo, de modo que a atuação do indivíduo no grupo fosse firmada na base da cooperação.

Além dos conteúdos atitudinais e procedimentais descritos no projeto original e dos conteúdos surgidos na medida em que se desenvolvessem os trabalhos de estudo e pesquisa de cada grupo, cada uma das disciplinas envolvidas, com exceção da Informática a quem caberia o papel de suporte, chamaria a atenção para os seguintes blocos de conteúdos conceituais:

- Biologia: biodiversidade e ecossistemas;

- Filosofia: ética e cidadania

- Física: energia;

- Geografia: impactos ambientais;

- História: o ciclo da borracha - o apogeu da Amazônia;

- Química: créditos de carbono.

\section{AS BASES DE UMA CONTROVÉRSIA CONTROLADA}

Havendo a percepção de existência de uma controvérsia, é necessário estabelecer um processo sistematizado em que se consiga tanto ensinar quanto aprender. É o momento de "colocar as primeiras regras do jogo", como, por exemplo, o trabalho em grupo, a essencialidade de fundamentação rigorosa das posições colocadas etc.

Nesse trabalho, a leitura dos textos foi seguida de uma provocação instada pela análisedos impactos da exploração da biodiversidade da floresta sobre a preservação ambiental, além do custo social que seria gerado por uma possível internacionalização da Amazônia.

Nesse caso, a controvérsia foi dimensionada como de amplitude internacional, dados os interesses envolvidos, e então, foram definidos cinco atores e suas atribuições, a saber: 
- O Governo Brasileiro: defender sua soberania e apresentar-se como absolutamente capaz de levar a cabo tanto a preservação da Floresta como a exploração responsável dos recursos lá existentes;

- O Movimento Ambientalista: organização não governamental mantida por contribuições espontâneas e com atividades de voluntários, tendo por objetivo defender a internacionalização da Amazônia, com vistas ao desenvolvimento de práticas de preservação do meio ambiente, ante a inépcia do Governo Brasileiro, colocando-se em uma posição, embora contrária à da Associação das Indústrias, dissonante dos interesses nacionais;

- A Associação das Indústrias interessada em explorar a floresta: conjunto de indústrias que visam a explorar as pretensas riquezas existentes na floresta, alijando mecanismos que impeçam a criação de qualquer tipo de restrição à implantação de indústrias e à pesquisa científica na Floresta Amazônica, alegando, para tal, a ideia de que restrições prejudicarão o desenvolvimento da ciência e o emprego de técnicas modernas de preservação do meio ambiente;

- Os Povos da Floresta: constituída pelos moradores da região, especialmente os indígenas, interessados em preservar seus costumes, sua terra, mas ao mesmo tempo auferir beneplácitos advindos de uma forma cuidadosa de exploração da floresta.

- O Grupo de Trabalho responsável pela organização da Conferência Mundial sobre a Internacionalização da Amazônia: organizar uma conferência em que deverá ser debatida a internacionalização da Amazônia e suas consequências, ouvindo todas as partes envolvidas, sem deixar de considerar a legislação já existente e as tendências internacionais sobre o assunto; é, portanto, o mediador e moderador da controvérsia, cabendo-lhes ainda a tarefa de preparar os procedimentos posteriores à decisão de internacionalização ou não da Amazônia, respeitando o interesse pessoal em detrimento da vontade social.

\section{RESULTADOS OBSERVADOS}

Ao lançar mão da controvérsia controlada como uma ferramenta didática de amplo espectro metodológico, foi possível estimular a passagem do nível de conhecimento superficial acerca do tema, restrito aos dados de senso comum, pouco consistentes, e repletos de relações de causa e efeito pouco claras, para um nível em que os alunos foram instados a 
dar pujançaao domínio das informações com que trabalharam e compuseram sua base argumentativa.

Outrossim, aos noveprofessores participantes também foi imputado um fazer pedagógico distinto do usual por meio de um trabalho de natureza incomum, mas que foi bem recebido e causoubom impacto junto aos alunos, especialmente pela possibilidade de trazer questões contemporâneas para a sala de aula, bem como estimular a participação discente de forma efetiva, tão defendida, porém pouco realizada.

A postura assumida pelos professores, que atuaram precipuamente como orientadores de estudos e pesquisas, deixando aos alunos o protagonismo da curiosidade epistêmica (CABALLERO, 2000), foi fundamental para quebrar um tabu que ainda persiste em muitas escolas de que somente é possível aprender quando o professor está na frente da sala, dando a aula. Em vez disso, o processo de ensino pode implicar o processo de aprendizagem, sim, não sendo condição necessária e suficiente que aquele esteja centrado no professor e, este, no aluno. Segundo Tapscott (1998):

"O importante é compreender que, ao mudar de uma educação centrada no
professor para uma educação centrada no aluno, não significa que, de repente, o
professor desempenha um papel menos importante. [...] A educação centrada no
aluno o motiva a aprender e se converte em momentos prazerosos para ele".

As observações possibilitaram depreender a quebra do paradigma da tradicional forma estabelecida como padrão de ensino escolar - a aula expositiva. Foi o que Lipman chamou de “paradigma-padrão da prática normal” (LIPMAN, 2001, citado por TONIETO, 2006).

Ademais, pode-se inferir também que as observações de satisfação devem ser creditadas ao cumprimento das cinco prerrogativas, enunciadas por ABREU e MASETTO (1990), para se ter uma aprendizagem de fato significativa:

“a) haver situações de aprendizagem em que possam envolvê-lo como um todo ideias, sentimentos, cultura, etc. (conhecimentos, experiências, vivências, problemas, confronto experiencial com problemas práticos, participação no processo, modificações de comportamento entre outras situações);

b) ser pessoal no sentido de suscitar a mudança de comportamento ou da condição inicial de aprendizagem em que o aluno se encontrava;

c) visar objetivos realísticos tanto para o aluno (significativo) quanto para o curso/programa/aulas (atingíveis);

d) ser acompanhada de feedback imediato, enquanto elemento que possibilite tanto ao professor orientador quanto ao aluno condições para corrigir e reiniciar a aprendizagem;

e) ser embasada em um bom relacionamento interpessoal, entre todos os participantes - o diálogo, a participação, a colaboração, o clima de confiança, devem permear as relações." 
Portanto, professores e alunos puderam exercer papéis de destacada relevância na estruturação, preparação e desenvolvimento da controvérsia controlada, tema deste artigo. Voltando à definição dada por Chrispino (2008), àqueles coube fazer as partes (1), (2) e (3), e a estes, as parte (3), (4), (5), (6) e (7).

\section{CONCLUSÕES}

Conforme afirma Chrispino (2008), “a Abordagem CTS é certamente provocadora de reflexões". Foi por meio de sua utilização que um grupo de adolescentes, capitaneados por nove professores, pode analisar com riqueza de detalhes e, por conseguinte, refletir sobre um problema de peso internacional de severos impactos sociais, científicos e tecnológicos de uma forma organizada e metodologicamente controlada.

Este trabalho foi iniciado pelo desejo de investigar se a controvérsia controlada poderia ser utilizada como uma ferramenta didática para discussão do CTS com vistas à incorporação de uma cultura científica no Ensino Médio, além de interferir como elemento de incentivo para a aprendizagem significativa e a interdisciplinaridade.

Conquanto existissem resistências, especialmente centradas na quebra de uma forma tradicional de práxis pedagógica, concluímos que o exercício para os alunos do trabalho em grupo a fim de construir argumentações em torno de uma posição por vezes distante daquela em que se acredita, a necessidade do estabelecimento de consenso em meio a posições divergentes, a seleção e o tratamento de informações, enfim, a mobilização de um conjunto de habilidades e competências pessoais, relacionais e profissionais, cada vez mais demandadas na sociedade contemporânea, foram essenciais para a consecução da investigação inicialmente pretendida.

Com isso, verificamos que a controvérsia simulada, planejada rigorosamente dentro de seus pressupostos originais, se constitui em um poderoso recurso didático para $\mathrm{o}$ desenvolvimento de processos de ensino e de aprendizagem em sala de aula, possibilitando aos professores envolvidos atuarem de maneira distinta daquela em que eles são apenas expositores de informações.

Outrossim, afora a teatralidade que tanto encanta uma parte expressiva de nossa juventude, nos debates ocorridos durante as sessões públicas, houve exposições plenas, densas e muito bem estruturadas, resultantes de cuidadosos e laboriosos trabalhos de estudos e 
pesquisas realizados pelos alunos sob a orientação cuidadosa e minuciosa dos professores responsáveis pelo projeto.

Pela própria natureza do trabalho, desde o início, teve-se ação interdisciplinar. As questões destacadas por cada disciplina foram abordadas, bem como uma série de outras que surgiram na medida em que o projeto foi se desenvolvendo. $\mathrm{O}$ concurso de conhecimentos foi essencial para a compreensão do tema e para a construção dos argumentos que foram elencados.

Enfim, desenvolveu-se um trabalho que não se limitou ao que Santos e Mortimer (2000) chamam de uma proposta de CTS que enfatiza“"[...] um modelo de tomada de decisão tecnocrática em relação a custos e benefícios, as quais enfatizam muito mais passos racionais na tomada de decisão do que desenvolvimento de valores para ação responsável que seria requerido em uma perspectiva humanística na visão freireana”.

De modo geral, recorrendo à máxima popular, "só se aprende fazendo", tanto para alunos como para professores, o projeto realizado permitiu a aprendizagem por meio da atuação, de sorte que, como diz Chrispino (2008),

\begin{abstract}
A participação social só se aprende participando... criemos os espaços de participação para que os nossos alunos simulem as dificuldades que poderão viver proximamente e, quando estivermos ofertando a eles as simulações da realidade e oferecendo as ferramentas do conhecimento que transforma, estaremos oferecendo a nós mesmo o que não tivemos antes. A cada controvérsia controlada que coordenarmosestaremos abrindo janelas de novas percepções aos jovens sob nossa direção e estaremos reafirmando a nós mesmos que uma sociedade melhor é possível.
\end{abstract}

Enfim, a estratégia de ensino por meio da controvérsia controlada, neste trabalho, desvelou-se ser um diferencial de viés positivo na consecução efetiva das relações entre os principais atores escolares - professores e alunos. A forma como tanto um quanto o outro se integraram e se engajaram no projeto sobre a internacionalização da Amazônia representou uma indicação da relevância de atuar de maneira cidadã em processos decisórios de cunho tecno-científico. Ademais, a possibilidade de confrontar-se na busca de outros conhecimentos, além dos curriculares, trouxe à baila a quebra da ideia pueril, de base empirista, de a ciência ser neutra e exata.

Com satisfação, comprovou-se que os alunos envolvidos puderam desenvolver competências pessoais imprescindíveis para a reflexão e a atuação consciente de seu protagonismo na sociedade atual como, por exemplo, ser bom orador e bom ouvinte, saber 
estabelecer prioridades nas tarefas que tem para executar,mostrar-se disponível para antecipar soluções, dentre outras.

\section{REFERÊNCIAS}

ABREU, M. C. e MASETTO, M. T. O professor universitário em aula. São Paulo. Cortez, 1993.

AIKENHEAD, G. STS Education: A Rose by Any Other Name. In: CROSS, R. (Ed.): A Vision for Science Education: Responding to the work of Peter J. Fensham, New York: RoutledgeFalmer, 2003.

ALBE, V. Tratar controversias científicas contemporâneas em clase.Alambique - Didactica

BRASIL. Ministério da Educação e Cultura. (1998). Parâmetros Curriculares Nacionais. Brasília: MEC

CABALLERO, A. Transformar losconflictos: una apuesta. Tarbiya: revista deInvestigación e Innovación Educativa,Madrid, n. 25, p. 104, 2000.

CASASSUS, J. A Escola e a Desigualdade - 2 ed. Brasília: Líber Livro Editora, UNESCO, 2007. p. 79

CHRISPINO, A. Ciência, Tecnologia e Sociedade. Módulo do Curso de Especialização em Educação Tecnológica, UAB/CEFET-RJ, aula 11. Mimeo, 2008.

CHRISPINO, A. Proibição do fumo: Decisão pessoal ou social? Uma abordagem de ensino CTS para o tema tabagismo a partir da simulação de controvérsia controlada. Disponívelem http://www.oei.es/salactsi/alvaro.pdf

CRESWELL, J. Qualitative Inquiry and Research Design: Choosing among Five Traditions. Thousand Oaks, CA: Sage Publications, 1998

CUTCLIFFE, S. Ciencia, tecnología y sociedad: un campo interdisciplinar, In: MEDINA, M. y SANMARTÍN, J. (eds.) Ciencia, tecnología y sociedad: Estudios interdisciplinares em launiversidad, em laeducación y em lagestión pública, Barcelona: Anthropos, 1990

DEMO, Pedro. Aprender: o desafio reconstrutivo. Boletim Técnico do SENAC, Rio de Janeiro, v. 24, n. 3, set./dez., 1998. p. 33

EPSTEIN, Isaac. Aquecimento global. Comciência, Reportagens. SBPC/Labjor, Brasil 2002. Disponível em: http://www.comciencia.br/reportagens/clima/clima11.htm

FIGUEIREDO, O. A controvérsia na educação para a sustentabilidade: uma reflexão sobre a escola do século XXI. Revista Interacções, n.4, 2006. Disponível em http://www.eses.pt/interaccoes.

GIDDENS, A. Risco, Confiança, Reflexividade. In: Modernização Reflexiva: política, tradição e estética na ordem social, Orgs. Beck, U., Giddens, A. Lash, S., São Paulo, Ed. UNESP, 1997.

GORDILLO, M. Metáforas y simulaciones: alternativas para ladidáctica y laenseñanza de lasciencias. Revista Electrónica de Enseñanza de lasCiencias, Vol. $2 \mathrm{~N}^{\circ} 3,2003$. Disponível em http://saum.uvigo.es/reec/volumenes/volumen2/Numero3/Art10.pdf 
LÜDKE, M. ANDRÉ, M.ED.A. Pesquisa em Educação: abordagens qualitativas. 9. ed. São Paulo: EPU, 1986

MACHADO, N. J. Educação: competência e qualidade - 2 ed. - São Paulo: Escrituras Editora, 2010.

MARTINS, G. de A. Estudo de Caso: Uma Estratégia de Pesquisa. São Paulo, Editora Atlas, 2006

REIS, P. R dos, A Escola e as Controvérsias Socio-científicas - perspectivas de Alunos e Professores, Coleção Educação 1, Escolar Editora, Lisboa, 2008.

REIS, P., GALVÃO, C. Controvérsias sócio-científicas e prática pedagógica de jovens professores. Investigações em Ensino de Ciências, Instituto de Física, UFRGS. Vol. 10, N. 2, junho de 2005. Disponível em http://www.if.ufrgs.br/public/ensino/vol10/n 2/v10_n2_a1.htm (Acesso em 10/10/2009).

SANTOS, W. L. P. dos; MORTIMER, E. F. Uma análise de pressupostos teóricos da abordagem C-TS (Ciência-Tecnologia-Sociedade) no contexto da educação brasileira. Ensaio: pesquisa em educação em ciências, v. 2, n. 2, 2000.

TAPSCOTT, D. Creciendoenun entorno digital: La generación Net, Bogotá. Mc Graw Hill, 1998

TERRAZAN, E.A, IAMARQUE, T., PICCINI, I. P., FAGUNDES, S. M. K., Produções em Educação em Ciências sob a perspectiva CTS/CTSA. VII ENPEC, 2009, disponível em http://www.foco.fae.ufmg.br/viienpec/index.php/enpec/viienpec/paper/viewFile/1120/511

THIOLLENT, M. Metodologia da Pesquisa-Ação. São Paulo, Ed. Cortez, $3^{\text {a }}$ edição,1986.

TONIETO, C. A prática dialógica na comunidade de investigação: possibilidades de uma educação para o pensar. In: II Seminário Nacional de Filosofia e Educação - Confluências, 2006, Santa Maria RS. II Seminário Nacional de Filosofia e Educação - Anais/Artigos Completos. Santa Maria - RS :Facos, 2006. Disponível em http://www.ufsm.br/gpforma/2senafe/PDF/002e1.pdf

ZABALA, A. A prática educativa: como ensinar. Porto Alegre: Artmed, 1998. 